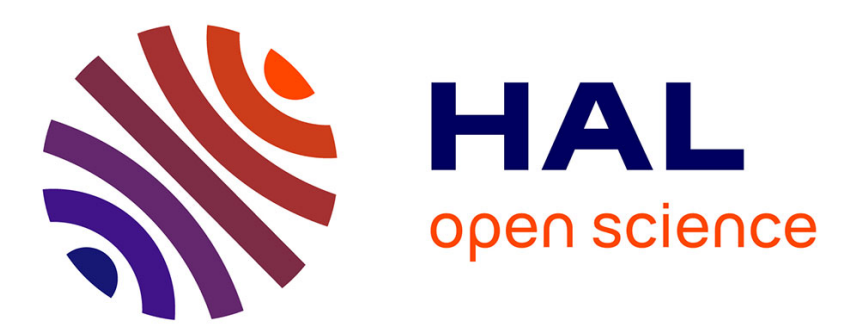

\title{
From goals to muscles: motor familiarity shapes the representation of action-related sounds in the human motor system
}

Luca Ticini, Simone Schütz-Bosbach, Florian Waszak

\section{- To cite this version:}

Luca Ticini, Simone Schütz-Bosbach, Florian Waszak. From goals to muscles: motor familiarity shapes the representation of action-related sounds in the human motor system. Cognitive Neuroscience, 2019, 10 (1), pp.20-29. 10.1080/17588928.2018.1424128 . hal-02384440

\author{
HAL Id: hal-02384440 \\ https://hal.science/hal-02384440
}

Submitted on 3 Dec 2019

HAL is a multi-disciplinary open access archive for the deposit and dissemination of scientific research documents, whether they are published or not. The documents may come from teaching and research institutions in France or abroad, or from public or private research centers.
L'archive ouverte pluridisciplinaire HAL, est destinée au dépôt et à la diffusion de documents scientifiques de niveau recherche, publiés ou non, émanant des établissements d'enseignement et de recherche français ou étrangers, des laboratoires publics ou privés. 
See discussions, stats, and author profiles for this publication at: https://www.researchgate.net/publication/322140038

From goals to muscles: motor familiarity shapes the representation of actionrelated sounds in the human motor system

Article in Cognitive neuroscience · December 2017

DOI: 10.1080/17588928.2018.1424128

CITATIONS

2

3 authors, including:

Luca F. Ticini, FRSA

The University of Manchester

36 PUBLICATIONS 736 CITATIONS

SEE PROFILE
READS

224

Florian Waszak

Université de Paris

133 PUBLICATIONS 3,184 CITATIONS

SEE PROFILE

Some of the authors of this publication are also working on these related projects:

Project instruction-based action control View project

Project Sensorimotor learning View project 


\section{From goals to muscles: motor familiarity shapes the representation of action-related sounds in the}

\section{human motor system.}

Luca F. Ticini ${ }^{1}$, Simone Schütz-Bosbach ${ }^{2}$, Florian Waszak $^{3}$

${ }^{1}$ Division of Neuroscience and Experimental Psychology, School of Biological Sciences, Faculty of Biology, Medicine and Health, University of Manchester, Manchester Academic Health Science Centre, Manchester M13 9PL, UK

${ }^{2}$ Department of Psychology, Ludwig Maximilians University Munich, Germany

${ }^{3}$ Université Paris Descartes and CNRS, Paris, France

Correspondence should be addressed to Luca F. Ticini, Division of Neuroscience and Experimental Psychology, Faculty of Biological, Medical and Health Sciences, The University of Manchester, Manchester M13 9PL, UK; luca.ticini@manchester.ac.uk

\section{ABSTRACT}

Numerous studies corroborated the idea that the sound of familiar motor acts triggers a muscle-specific replica of the perceived actions in the listener's brain. We recently contradicted this conclusion by demonstrating that the representation of newly-learned action-related sounds is not somatotopically organised but rather it corresponds to the goal a particular action aims to achieve. In the present study, we reconciled these contrasting results by showing that a higher degree of motor familiarity obtained via long-term practice with auditorymotor associations shapes a somatotopically organised representation of action-related sounds. We measured motor-evoked potentials (MEPs) to TMS as an index of the functional correspondence between the sensory stimulation and the activity in the listener's motor cortex. Participants heard two tones of different pitch, void of previous motor meaning, before and after an acquisition phase in which they generated these tones by performing 400 free-choice button presses. After that, we disentangled the representation of the action goal (button-tone association) from the somatotopic (muscle-tone) association by reversing the muscle-button contingencies. Our result supports the hypothesis that the neuronal representations of action-related sounds depends on motor familiarity: perceptuomotor representations of newly-learned actions are muscleindependent and corresponded to the button-tone contingencies; whilst longer-term practice results in representations that relied on lower-level intrinsic parameters associated with the kinematics of specific movements. 
Keywords: action; mirror neurons; transcranial magnetic stimulation; somatotopic; sound; motor familiarity

\section{INTRODUCTION}

Despite the most apparent function of the cortical motor areas being to generate voluntary movements, their activity is also measured in the absence of overt motor acts whilst observing actions executed by others. Such a functional equivalence between action execution and action perception was originally proposed by William James (James, 1890). Later on, it was experimentally substantiated by numerous studies in nonhuman and human primates (reviewed in Rizzolatti \& Craighero, 2004). Nowadays, it is generally accepted that the motor modulation (or motor resonance) associated with action perception reflects a neuronal process coding for the goal of other individuals' actions, as demonstrated in neurophysiological studies in non-human primates (Umilta et al., 2001; Kohler et al., 2002; Keysers et al., 2003) and in transcranial magnetic stimulation and fMRI experiments in humans (Cattaneo et al., 2009; Jastorff et al., 2010).

Nonetheless, the evidence gathered (reviewed in Aglioti and Pazzaglia, 2010) when the visual information is absent and actions are perceived only through their sound (such as when hearing someone breaking a nut) has generally failed to show goal-related modulations in the listener's brain (e.g., Ticini et al., 2017). Instead, measuring the neuronal discharge in response to action-related sounds usually revealed a faithful somatotopic (i.e., body part-specific) replica of the heard movements in a left fronto-parietal network (Pazzaglia et al., 2008; D’Ausilio et al., 2009; Möttönen and Watkins, 2009; Bangert and Altenmüller, 2003; Buccino et al., 2005; Gazzola et al., 2006; Lahav et al., 2007). A classical example of such muscle-specific motor pattern is the activity of the functionally defined hand motor area triggered by the sound of finger-clicks obtained in a rare intracranial EEG recording investigation conducted in an epileptic 12-year-old girl (Lepage et al., 2010a). Similarly, a magnetoencephalography study showed that the oscillatory activity associated with movement execution (cf. Salmelin \& Hari, 1994; Murthy \& Fetz, 1992) was also present after visual and auditory presentation of actions (Caetano et al., 2007). Other examples include hand clapping or finger tapping (Caetano et al., 2007; Aziz-Zadeh, Wilson, Rizzolatti, \& Iacoboni, 2006; Gazzola, Aziz-Zadeh, \& Keysers, 2006; Hauk, Shtyrov, \& Pulvermuller, 2006; Pizzamiglio et al., 2005; Aziz-Zadeh, Iacoboni, Zaidel, Wilson, \& Mazziotta, 2004), speech listening (Buccino et al., 2005; Tettamanti et al., 2005; Wilson, Saygin, Sereno, \& Iacoboni, 2004; Watkins, Strafella, \& Paus, 2003; Fadiga, Craighero, Buccino, \& Rizzolatti, 2002) and even piano playing (Lahav, Saltzman, \& Schlaug, 2007; D’Ausilio, Altenmüller, Olivetti Belardinelli, \& Lotze, 
2006; Bangert et al., 2005; Bangert \& Altenmüller, 2003; Lotze, Scheler, Tan, Braun, \& Birbaumer, 2003; Haueisen \& Knösche, 2001).

This functional correspondence between the auditory and motor aspects of actions has been further substantiated in patients with cortical injuries, and in healthy subjects by means of cortical inactivation. In both instances, impairing the execution of movements interfered with the recognition and categorisation of motor acts (Pazzaglia, Pizzamiglio, Pes, \& Aglioti, 2008; D’Ausilio et al., 2009; Möttönen \& Watkins, 2009). That is the case, for instance, in brain-damaged patients suffering from limb or buccofacial apraxia (i.e., the inability to perform specific gestures after left fronto-parietal damage), as they are unable to match representations of mouth or face-related actions with their corresponding sounds.

In an earlier transcranial magnetic stimulation (TMS) work, we tested the degree of somatotopicity in the listeners' motor cortex (Ticini et al., 2012) by measuring sound-related modulations during passive tone perception, before and after a short acquisition phase in which participants voluntarily triggered two tones by index and little finger button presses, respectively (Figure 1 in Ticini et al., 2012; see also, Elsner \& Hommel, 2001). Importantly, in a subsequent test phase we disentangled the action goal (generating a tone by pressing a button) from the movements used to achieve it by changing the position of the participants with respect to the buttons. As a consequence, the representation of the finger-button mapping (visible to the participant) was reversed relative to the trained one (Experiment 2 - reverse mapping, in Ticini et al., 2012). The results demonstrated, to our knowledge for the first time, that a functional correspondence between the sounds and their associated actions is established very rapidly (after only 200 trials or 3 to 5 minutes) and, most interestingly, that in the reversed finger-button mapping condition the perception of each tone facilitated the action needed to produce it rather than the movement that was associated with the tone during the training phase. This was a clear indication that the cortical activity reflected a motor representation of the goal of the action (pressing a button to generate a sound in the current context) rather than the movements learned during the training.

In the present study, we aimed at assessing whether we could reconcile these results with the evidence arguing for a somatotopic motor activation during passive listening to action-related sounds. We hypothesised that familiarisation (i.e., increasing the number of trials during training to 400 trials or 6 to 10 minutes) with the experimental setup and its goals is key in determining the outcome of our experiment, as it is known that the correspondence between action execution and action perception is sensitive to previous perceptuomotor 
experience (e.g., Aglioti, Cesari, Romani, \& Urgesi, 2008; Calvo-Merino, Grèzes, Glaser, Passingham, \& Haggard, 2006; Cross, Hamilton, \& Grafton, 2006), including semantic differences (e.g., between ripping paper and vocalisation) and anticipation effects (e.g., predictability of a sequence of notes in a rehearsed piano melody; e.g., Lahav et al., 2007; D’Ausilio et al., 2006).

In particular, also drawing from the motor learning literature (reviewed in Hikosaka et al., 1999), we expected that newly-trained sensorimotor associations are coded in an abstract goal-directed way (mainly relying on extrinsic coordinate frames, such as the position of the buttons and the association between each button and its corresponding tone). Indeed, as executing an action in the environment often results in kinematically different motor acts producing the same sensory effects (or goals), the corresponding motor representation must be independent of the muscle that might be used to do so. Instead, we expected that longterm practice would result in effector dependency (relying on intrinsic coordinate frames that refer to the specific motor patterns associated with the sounds during training). As a matter of fact, if the association is over-learned, sensorimotor associations may tend to become more stable and consolidated (Walker et al., 2003; Krakauer and Shadmehr, 2006) in a somatotopically organised manner.

Relying on our previous results (Ticini et al., 2012), we predicted that each training associating selfgenerated actions with arbitrary sounds would generate action-sound representations that would become apparent as a new pattern of finger-specific motor facilitation (e.g., Aziz-Zadeh et al., 2004; Watkins et al., 2003; Fadiga et al., 2002). In particular, we expected to demonstrate that a longer training in the acquisition phase can reverse the pattern of results associated with newly-trained associations: that is, each tone would facilitate the motor program that was associated with it in the training.

To demonstrate that, we recorded motor-evoked potentials (MEPs) to single magnetic TMS pulse applied over the left primary motor cortex of healthy volunteers (see Methods). We recorded MEPs from the hand muscles specifically involved in the acquisition phase: the abductor digiti minimi (ADM; little finger muscle) and first dorsal interosseous (FDI; index finger muscle). This experimental approach allowed to measure the correspondence between auditory and motor codes in the listener's motor system at the time the TMS impulse was applied. 


\section{METHODS}

\section{Participants and Experimental Protocol}

The experiment was carried out on ten right-handed healthy undergraduate students (required size determined through the $\mathrm{G}^{*}$ power software as described in the Supplementary Methods; Faul, Erdfelder, Buchner, \& Lang, 2009) who were naive to the purpose of the experiment, with ethical-committee approval and informed written consent.

We employed the same experimental equipment and setting described in Ticini et al. (2012). Briefly, participants sat comfortably with their forearms on a table. They were asked to observe their right hand throughout the experiment, which was positioned between two buttons (starting position): one located on the right side of the little finger and the other on the left side of the index finger. The experiment started with an Experimental Baseline (EB; Figure 1), in which we tested pre-existing motor modulations in response to action-related sounds by recording motor evoked potentials (MEPs) whilst participants passively listened to two tones of different pitch (see Supplementary Methods). Then, in an Acquisition Phase (AP), they trained to contingently associate two button presses with two corresponding tones (those already heard in EB) by performing 400 free-choice button presses by abducting (from the starting position) the index finger (to press the left button) or the little finger (to press the right button). These movements maximised the activity of the first-dorsal interosseous (FDI) and the abductor digiti minimi (ADM) muscles, respectively. The assignment of tones (high vs. low) to each button (left vs. right) of the AP was randomised and counterbalanced across participants. In other words, for half of the participants, the high tone was associated with the left button and the low tone with the right one. In the other half, the high tone was associated with the right button and the low tone with the left one. A Test Phase (TP) followed, in which MEPs were acquired whilst participants passively listened to the same tones as in EB.

In both EB and TP, during each trial we simultaneously recorded two MEPs (one from FDI and one from $\mathrm{ADM}$ ) in response to single transcranial magnetic stimulation (TMS) pulses applied over each participant's right hand representation in the left primary motor cortex (see Supplementary Methods). In TP, each MEP was labeled as either "Congruent" or "Incongruent" (CONGRUENCY factor) in the following way. If in a trial the tone heard was previously associated (in the AP) to the left button then the MEPs recorded from the FDI were labeled as "Congruent". Indeed, in AP this tone was associated to left button-presses and required an index finger movement (i.e. activity of the FDI muscle). On the contrary, the MEPs recorded in this trial 
from the ADM were labeled as "Incongruent" (given that that the little finger's movement was not associated to that sound during AP). The opposite labelling was assigned for trials with tones that were elicited by right button presses during AP (i.e., tones that were generated by little finger movement or activity of the ADM muscle): MEPs recorded from the ADM were labeled as "Congruent" while those recorded from the FDI were labeled as "Incongruent". Thus, in each TMS trial in TP, one of the (simultaneously measured) muscles was associated with the presented tone, and the other was not (see also Ticini et al., 2012).

Importantly, in TP, in order to dissociate the representation of the button-tone relationship (each button generates a specific tone) from that of the muscle-tone relationship (each tone is triggered by the movement of a particular muscle), the participants moved to the other side of the table (i.e., they rotated $180^{\circ}$ from the AP position, as depicted in Figure 1). In this new position, their hands were again placed between the two buttons, but this time the finger-button mapping was opposite to that trained in AP. Participants underwent no further training according to their new seating position. Instead, they passively listened to the tones generated during the previous AP, presented in random order. The buttons were differently coloured (blue and yellow) to make more explicit the fact that the finger-button mapping had changed.

Overall, in TP the CONGRUENCY factor encoded the somatotopic mapping effect (trials congruent with the finger-button mapping trained in AP). To ensure that the effect was not driven by a particular muscle (FDI or ADM), the factor MUSCLE encoding the muscle from which the MEP was recorded was also used for data analysis.

\section{-Figure 1 about here--}

\section{Data analysis}

MEP amplitudes were normalised (z-scores) to the average MEP amplitude recorded for each participant, muscle and session (see Supplementary Methods and Table S1). Statistical analysis was performed separately for each session using mean normalised MEP as dependent variable in repeated measures ANOVAs. In EB, TONE (Tone 1 or Tone 2) and MUSCLE (FDI or ADM) were within-participants factors. In TP, CONGRUENCY (Congruent or Incongruent tone; in EB, these factors refer to the future muscle tone combinations) and MUSCLE (FDI or ADM) were within-participants factors. We used the partial eta squared $\left(\eta p^{2}\right)$ to determine the effect size and set the alpha level at 0.05 for all statistical tests. We also computed Bayes Factors (BF; Rouder, Morey, Speckman, \& Province, 2012) in JASP (Love et al., 2015) to estimate the 
likelihood of the null hypothesis relative to the alternative hypothesis (Rouder, Speckman, Sun, Morey, \& Iverson, 2009).

\section{RESULTS}

In $\mathrm{EB}$, no significant results were found (all $\mathrm{F}$ statistics had p-values $>0.6$ ). This excluded that the auditory stimuli were associated with an action before the beginning of the experiment. Instead, in TP the main effect of CONGRUENCY was statistically significant $\left[F(1,9)=5.18, p<0.05, \eta p^{2}=0.37\right]$, whilst the main effect of MUSCLE and the interaction between CONGRUENCY and MUSCLE were not (all F statistics had p-values $>0.5$ ). A bayesian repeated measures ANOVA (Love et al., 2015) with default prior scales revealed that the main effect model of CONGRUENCY was preferred to the interaction model by a BF of 4.6. This provided further evidence in favour of the hypothesis of a main effect of CONGRUENCY by a ratio of 4.6:1. This outcome indicated that the pattern of MEP reflected the associations trained in AP in a muscle-specific manner (Figure 2). In particular, the mean normalised MEPs measured in the Congruent condition were larger when compared to the Incongruent condition (i.e., the pattern was the same to that trained in AP, instead of being goal-directed as that in Ticini et al., 2012).

-Figure 2 about here--

\section{DISCUSSION}

In the present study, we investigated whether the degree of sensorimotor familiarity shapes the representation of action-related sounds in the adult human motor system. To achieve this, we employed a twoactions / two-muscle paradigm in which in an Acquisition Phase (AP in Figure 1) participants learned to generate two different tones (without previous motor, verbal, or semantic meaning, as demonstrated by the null results in EB) by using two muscles executing two actions (Figure 1). Then, in a Test Phase (TP), we recorded the sound-related covert activation of the listeners' motor cortex after having reversed the fingerbutton contingencies.

The result demonstrated that intensive practice or familiarisation with sensory-motor associations (i.e., 400 trials or 6 to 10 minutes) resulted in effector dependency. This outcome was opposite to what expected 
from our previous work (Ticini et al., 2012), in which newly-trained sensory-motor associations were coded in an abstract and goal-specific manner. In other words, in our earlier experiment, passive listening to tones specifically facilitated the motor program that should have generated them in the reversed context. For instance, MEPs recorded from each muscle, instead of being larger for the tone associated to it during AP (Congruent condition), they were larger for the other tone (Incongruent condition). Here we observed the opposite pattern of MEPs: each tone elicited larger MEPs in the same muscle that previously triggered it in AP (Congruent condition) when compared to the MEPs recorded from the other muscle (Incongruent condition). What does this outcome represent?

When we repeat a motor act that is causally followed by a sensory outcome, synaptic potentiation can establish a stable correspondence (Hebb, 1949; Keysers and Perrett, 2004; Keysers et al., 2014) between action and perception. In turn, this association can be used in the reverse direction when a movement is induced by anticipating or perceiving its sensory effects (Herwig et al., 2007; Schütz-Bosbach \& Prinz, 2007; Hommel, Müsseler, Aschersleben, \& Prinz, 2001; James, 1890). We have previously demonstrated (Ticini et al., 2012) that even a short, minute-based training of voluntary self-executed actions suffices to the brain to obtain an accurate knowledge about the permanent features of the experimental setup that we employed: that is, the association between a tone and the corresponding button. The tests executed clearly argued that the motor system holds a muscle-independent representation of the actions participants trained, which takes into account the extrinsic coordinate frames for the accomplishment of the goal of the action (i.e., for the act of generating a particular tone by pressing a specific button). For this reason, in the reversed Test Phase of our earlier work, we found that the tones elicited larger MEPs in the Incongruent condition when compared to the Congruent one. Here, we went a step forward and showed that this is only true when a limited number of associative training trials is rehearsed. Indeed, when participants obviously over-familiarised with the setup, the MEPs recorded covertly replicated the kinematics of movements trained in AP.

The importance of these results lies in the reconciliation of a role of the motor cortex in goal coding with the high degree of somatotopicity observed during the perception of action-sounds (see Introduction). This to say that just changing the length of associative learning paradigms (in our case from 3 to 5 min to 6 to $10 \mathrm{~min}$ ) may have different outcome on the representation of perceived actions in the human brain. When we use to perform goal-directed actions with multiple effectors (for instance, switching the light on with the index 
finger, a second time with the elbow if we are holding something in our hands, and so on) it is likely that the representation obtained is higher-order and independent from the muscles used. When, instead, we over-learn the association of a specific muscle movement with its perceivable consequences (as it may happen in sports; see also Wolpert, Diedrichsen \& Flanagan, 2011), the representation in the brain may become effector specific. Such a phenomenon has been observed also in the brain of non-human primates, albeit in the domain of learning of movement sequences, where newly-learned sensorimotor sequences, after a long-term practice, become largely effector-dependent (Hikosaka et al., 2002). This idea is also in agreement with theories of motor learning (Hikosaka et al., 1999, 2002) that propose that newly-trained sensory-motor memories are coded in an abstract way in which visual-spatial coordinates play a major role. Instead, long-term practice results in effector dependency: in other words, for over-learned movements the specific activation patterns of the agonist and antagonist muscles take over. This theoretical scheme involves a fast and slower developing component that, during practice, would transform motor memories that were relying on spatial coordinates into memories that depends on body part-specific motor coordinates. One possible justification for this alteration is that relying on motor coordinates would enable a faster and more accurate performance (Hikosaka et al., 1999), which does not require spatial transformations and therefore demands a reduced amount of neural computation. Our results are also consistent with training-induced motor plasticity as observed in other studies (D’Ausilio et al., 2006; Classen et al., 1998). For instance, Classen and colleagues (Classen et al., 1998) demonstrated that 5 or 10 min of continuous training may establish changes that encode the kinematic details of a practiced movement. According to these authors this phenomenon "may be regarded as a short-term memory for movement and be the first step of skill acquisition".

It is also likely that these two types of sensorimotor representations (goal directed or kinematically oriented) are acquired independently, for instance by two neural system working in parallel. However, to our knowledge, no data in this regard are available. Neuroimaging studies in humans have shown that the sensory outcome of an action trigger activity in a temporal-parietal-ventral network of premotor and somatosensory areas, and the cerebellum (Rizzolatti and Matelli, 2003; see also Waszak et al., 2005; Herwig, Prinz \& Waszak, 2007; Melcher et al., 2008). Some of these areas were identified as responsive to action-effects in neurophysiological studies in the animal brain, as well (Umilta et al., 2008; Kakei et al., 1999, 2001). Whether these areas are also involved during the perception of the effects of over-learned motor acts is unclear as these 
experiments didn't vary the amount of training required to establish these sensorimotor associations. Nonetheless, some work in the field of motor skills learning (reviewed in Hikosaka et al., 2002) suggested that dynamic interactions of networks composed of fronto-parietal cortices, basal ganglia and cerebellum would be able to acquire the same motor skill in different coordinates. As a matter of fact, TMS studies have demonstrated that the activity recorded from the primary motor cortex is modulated by the goal (e.g., Fadiga, Fogassi, Pavesi, \& Rizzolatti, 1995) as well as the movements of perceived actions (Cattaneo et al., 2009). But these variations in corticospinal excitability may be driven by premotor cortices to which the primary motor cortex has strong reciprocal connections (Dum \& Strick, 2005; Shimazu, Maier, Cerri, Kirkwood, \& Lemon, 2004; Matelli, Camarda, Glickstein, \& Rizzolatti, 1986).

For instance, experiments (reviewed in Fernandino \& Iacoboni, 2010; Gentilucci \& Dalla Volta, 2008) have reported that the pars opercularis of the inferior frontal gyrus as well as the inferior parietal lobule encode extrinsic features (e.g., the relative position of the target and the hand in space) related to action goals, whilst the ventral premotor cortex encodes the lower-level intrinsic parameters (e.g., specific muscle, joint, and digit movements) related to specific motor acts. For instance, in an fMRI study in which participants were presented with video clips of an agent executing different motor acts with different effectors (foot, hand, and mouth), the clusters of activation in the premotor cortex were grouped according to the effectors performing the actions observed, whilst in the inferior parietal lobule the perceived actions were coded in therms of the relationship between the agent and object (e.g., bringing the object toward the agent or moving it away), regardless of the effectors used (Jastorff et al., 2010). This reliance on extrinsic reference frames was also demonstrated in the motor cortex neurons of the monkey brain (Graziano \& Aflalo, 2007; Graziano, 2006; Graziano et al., 2002; Umilta et al., 2001, 2008; Kakei, Hoffman, \& Strick, 2001, 2003; Kakei et al., 1999; Alexander \& Crutcher, 1990a, 1990b; Rizzolatti et al., 1988).

Although the finding of our work may be relevant in defining that the nature of sensory-motor representations (i.e. goal-oriented or somatotopic) depends on training duration, thus potentially providing a unifying framework for previous apparently contradictory findings, we should highlight that a stronger conclusion could have been obtained by running a longitudinal study in which the same group of participants was tested at different points in time during the training. 
To conclude, our result suggests that the concept of somatotopicity alone is inadequate to explain how perceived actions are mapped onto the motor system (e.g., Graziano \& Aflalo, 2007; Graziano, 2006; Schieber, 2001; Fadiga, Fogassi, Gallese, \& Rizzolatti, 2000; see also Fernandino \& Iacoboni, 2010). Furthermore, it indicates that the degree of somatotopicity measured in previous work may depend on the length of training of an association between an action and its perceivable consequences. As our data cannot establish the source of the modulation observed, we advocate for more research investigating the early and late learning stages of associative learning to identify how they are implemented in the human brain by, for instance, targeting with brain stimulation techniques the ventral and parietal premotor cortices as two possible sources of these different associative phenomena.

\section{FIGURES}

Figure 1. Illustration of the Experiment. In an Experimental Baseline (EB), we tested pre-existing motor modulations in response to action-related sounds by recording TMS-induced MEPs from the abductor muscles of the index and little fingers during passive listening to two tones of different pitch presented in a random order. During an Acquisition Phase (AP), participants voluntarily triggered the same two tones by index and little finger button presses. In a Reversed Test Phases (TP), the participants rotated $180^{\circ}$ from the AP position so that the representation of the finger-button mapping was reversed relative to the trained one. To investigate the sound-related modulations in the listener's motor cortex in TP, MEPs were again recorded from the muscles involved in the AP during passive tone perception.

Figure 2. Modulation of mean normalised MEP amplitudes (z-scores: mean \pm S.E.) recorded in EB and TP during passive tone listening. In TP in the Congruent condition, the MEPs were recorded from the muscle that in AP was associated with the presented tone, whilst the MEPs obtained from the non-associated muscle are represented in the Incongruent condition. In EB the pattern of MEPs excluded that the auditory stimuli were associated with an action before the beginning of the experiment. In TP, a statistically significant main effect of CONGRUENCY $(\mathrm{p}<0.05)$ and Bayesian analysis indicated that the MEPs were overall larger in the Congruent than in the Incongruent condition. Thus, each tone facilitated the action that generated it in AP. The 
result indicates that familiarity with the sensory effects of voluntary goal-directed actions dictates a somatotopic representation of sounds of other individuals' actions in the listener's motor cortex.

\section{REFERENCES}

Aglioti, S.M., Cesari, P., Romani, M., Urgesi, C. (2008). Action anticipation and motor resonance in elite basketball players. Nat Neurosci, 11, 1109-16.

Aglioti, S.M. \& Pazzaglia, M. (2011) Sounds and scents in (social) action. Trends Cogn. Sci., 15, 47-55.

Alexander GE, Crutcher MD (1990a) Neural representations of the target (goal) of visually guided arm movements in three motor areas of the monkey. J Neurophysiol 64:164 -178.

Alexander, G.E., Crutcher, M.D. (1990b). Preparation for movement: neural representations of intended direction in three motor areas of the monkey. J Neurophysiol, 64, 133-150.

Aziz-Zadeh, L., Iacoboni, M., Zaidel, E., Wilson, S., Mazziotta, J. (2004). Left hemisphere motor facilitation in response to manual action sounds. Eur J Neurosci, 19, 2609-2612.

Aziz-Zadeh, L., Wilson, S. M., Rizzolatti, G., \& Iacoboni, M. (2006). Congruent embodied representations for visually presented actions and linguistic phrases describing actions. Current Biology, 16, 1818-1823.

Bangert, M. \& Altenmüller, E.O. (2003). Mapping perception to action in piano practice: a longitudinal DCEEG study. BMC Neurosci, 4, 26.

Bangert, M., Peschel, T., Schlaug, G., Rotte, M., Drescher, D., Hinrichs, H., Heinze, H.J. \& Altenmüller, E. (2005). Shared networks for auditory and motor processing in professional pianists: Evidence from fMRI conjunction. Neuroimage, 30, 917-926.

Caetano, G., Jousmäki, V., Hari, R. (2007). Actor's and observer's primary motor cortices stabilize similarly after seen or heard motor actions. Proc Natl Acad Sci USA, 104, 9058-9062.

Calvo-Merino, B., Grèzes, J., Glaser, D.E., Passingham, R.E., Haggard, P. (2006). Seeing or doing? Influence of visual and motor familiarity in action observation. Curr Biol,16, 1905-1910.

Cattaneo, L., Caruana, F., Jezzini, A., \& Rizzolatti, G. (2009). Representation of goal and movements without overt motor behavior in the human motor cortex: a transcranial magnetic stimulation study. The Journal of Neuroscience, 29(36), 11134-11138. 
Classen, J., Liepert, J., Wise, S. P., Hallett, M., \& Cohen, L. G. (1998). Rapid plasticity of human cortical movement representation induced by practice. Journal of neurophysiology, 79(2), 1117-1123.

Cross, E.S., Hamilton, A.F., Grafton, S.T. (2006). Building a motor simulation de novo: observation of dance by dancers. NeuroImage, 31, 1257-1267.

D’Ausilio, A., Pulvermüller, F., Salmas, P., Bufalari, I., Begliomini, C., \& Fadiga, L. (2009). The motor somatotopy of speech perception. Current Biology, 19, 381-385.

Dum, R.P., Strick, P.L. (2005). Frontal lobe inputs to the digit representations of the motor areas on the lateral surface of the hemisphere. J Neurosci, 25, 1375- 1386.

Elsner, B., \& Hommel, B. (2001). Effect anticipation and action control. Journal of Experimental Psychology: Human Perception and Performance, 27, 229 - 240.

Fadiga, L., Craighero, L., Buccino, G., Rizzolatti, G. (2002). Speech listening specifically modulates the excitability of tongue muscles: a TMS study. Eur J Neurosci, 15, 399- 402.

Fadiga, L., Fogassi, L., Gallese, V., \& Rizzolatti, G. (2000). Visuomotor neurons: Ambiguity of the discharge or 'motor' perception? International Journal of Psychophysiology: Official Journal of the International Organization of Psychophysiology, 35(2-3), 165.

Fadiga, L., Fogassi, L., Pavesi, G., \& Rizzolatti, G. (1995). Motor facilitation during action observation: A magnetic stimulation study. J Neurophysiol, 73, 2608-2611.

Faul, F., Erdfelder, E., Buchner, A. \& Lang, A. (2009): Statistical power analyses using G*Power 3.1: Tests for correlation and regression analyses. Behavior Research Methods, 41, 1149-1160.

Fernandino, L., Iacoboni, M. (2010). Are cortical motor maps based on body parts or coordinated actions? Implications for embodied semantics. Brain Lang, 112, 44-53.

Gazzola, V., Aziz-Zadeh, L., Keysers, C. (2006). Empathy and the somatotopic auditory mirror system in humans. Curr. Biol., 16, 1824-1829.

Gentilucci, M., \& Dalla Volta, R. (2008). Spoken language and arm gestures are controlled by the same motor control system. Q J Exp Psychol, 61, 944-957.

Graziano, M. (2006). The organization of behavioral repertoire in motor cortex. Annual Review of Neuroscience, 29, 105.

Graziano, M., \& Aflalo, T. (2007). Mapping behavioral repertoire onto the cortex. Neuron, 56, $239-251$. 
Graziano, M., Taylor, C., \& Moore, T. (2002). Complex movements evoked by microstimulation of precentral cortex. Neuron, 34,841 .

Haueisen, J., \& Knösche, T. R. (2001). Involuntary motor activity in pianists evoked by music perception. Journal of Cognitive Neuroscience, 13, 786-792.

Hauk O, Shtyrov Y, Pulvermueller F. The sound of actions as reflected by mismatch negativity: rapid activation of cortical sensory-motor networks by sounds associated with finger and tongue movements. Eur J Neurosci 2006; 23:811-821.

Hebb, D. (1949) The organisation of behaviour. Wiley.

Herwig, A., Prinz, W., \& Waszak, F. (2007). Two modes of sensorimotor integration in intention-based and stimulus-based actions. The Quarterly Journal of Experimental Psychology, 60(11), 1540-1554.

Hikosaka, O., Nakahara, H., Rand, M. K., Sakai, K., Lu, X., Nakamura, K., ... \& Doya, K. (1999). Parallel neural networks for learning sequential procedures. Trends in neurosciences, 22(10), 464-471.

Hikosaka, O., Nakamura, K., Sakai, K., \& Nakahara, H. (2002). Central mechanisms of motor skill learning. Current opinion in neurobiology, 12(2), 217-222.

Hommel, B., Müsseler, J., Aschersleben, G., Prinz, W., 2001. The Theory of Event Coding (TEC): a framework for perception and action planning. Behav. Brain Sci. 24 (5), 849-878.

Lahav, A., Saltzman, E., \& Schlaug, G. (2007). Action representation of sound: Audiomotor recognition network while listening to newly acquired actions. Journal of Neuroscience, 27, 308-314.

Lepage, J. F., Tremblay, S., Nguyen, D. K., Champoux, F., Lassonde, M., \& Théoret, H. (2010a). Action related sounds induce early and late modulations of motor cortex activity. NeuroReport, 21, 250-253.

Lepage, J. F., Tremblay, S., \& Théoret, H. (2010b). Early non-specific modulation of corticospinal excitability during action observation. European Journal of Neuroscience, 31(5), 931-937.

Lotze, M., Scheler, G., Tan, H.R., Braun, C. \& Birbaumer, N. (2003). The musician's brain: functional imaging of amateurs and professionals during performance and imagery. Neuroimage, 20, 1817-1829.

Love, J., Selker, R., Marsman, M., Jamil, T., Verhagen, A. J., Ly, A., et al. (2015). JASP (Version 0.6.6) [Computer software].

Kakei S, Hoffman DS, Strick PL (1999) Muscle and movement representations in the primary motor cortex. Science 285:2136-2139. 
Kakei S, Hoffman DS, Strick PL (2001) Direction of action is represented in the ventral premotor cortex. Nat Neurosci 4:1020-1025.

Kakei, S., Hoffman, D.S., Strick, P.L. (2003). Sensorimotor transformations in cortical motor areas. Neurosci Res, 46, 1-10.

Keysers, C., Kohler, E., Umilta`, M.A., Nanetti, L., Fogassi, L., and Gallese, V. (2003). Audiovisual mirror neurons and action recognition. Exp. Brain Res. 153, 628-636.

Keysers, C. and Perrett, D. I. 2004. Demystifying social cognition: a Hebbian perspective. Trends in Cognitive Science, 8(11): 501-507.

Keysers, C., Perrett, D. I., \& Gazzola, V. (2014). Hebbian learning is about contingency, not contiguity, and explains the emergence of predictive mirror neurons. Behavioral and Brain Sciences, 37(02), 205-206.

Kohler, E., Keysers, C., Umilta`, M.A., Fogassi, L., Gallese, V., and Rizzolatti, G. (2002). Hearing sounds, understanding actions: action representation in mirror neurons. Science 297, 846-848.

Krakauer, J. W., \& Shadmehr, R. (2006). Consolidation of motor memory. Trends in neurosciences, 29(1), 5864.

James, W. (1890). The principles of psychology. New York: Holt.

Jastorff, J., Begliomini, C., Fabbri-Destro, M., Rizzolatti, G., Orban, G.A. (2010). Coding observed motor acts: different organizational principles in the parietal and premotor cortex of humans. J Neurophysiol, 104, $128-40$.

Matelli, M., Camarda, R., Glickstein, M., Rizzolatti, G. (1986). Afferent and efferent projections of the inferior area 6 in the macaque monkey. J Comp Neurol, 251, 281- 298.

Melcher, T., Weidema, M., Eenshuistra, R. M., Hommel, B., \& Gruber, O. (2008). The neural substrate of the ideomotor principle: An event-related fMRI analysis. NeuroImage, 39(3), 1274-1288.

Möttönen, R., \& Watkins, K. E. (2009). Motor representations of articulators contribute to categorical perception of speech sounds. Journal of Neuroscience, 29, 9819-9825.

Murthy, V.N., Fetz, E.E. (1992). Coherent 25- to 35-Hz oscillations in the sensorimotor cortex of awake behaving monkeys. Proc Natl Acad Sci USA, 89, 5670-5674.

Pazzaglia, M., Pizzamiglio, L., Pes, E., \& Aglioti, S. M. (2008). The sound of actions in apraxia. Current Biology, 18, 1766-1772. 
Pizzamiglio L, Aprile T, Spitoni G, Pitzalis S, Bates E, D’Amico S, Di Russo F (2005) Separate neural systems for processing action- or non-action-related sounds. Neuroimage 24:852-861

Rizzolatti, G., \& Arbib, M. A. (1998). Language within our grasp. Trends in Neurosciences, 21, 188-194.

Rizzolatti, G., \& Craighero, L. (2004). The mirror-neuron system. Annual Review of Neuroscience, 27, 169192.

Rizzolatti, G., Matelli, M. (2003). Two different streams form the dorsal visual system: anatomy and functions. Experimental Brain Research, 153, 146-57.

Rouder, J. N., Morey, R. D., Speckman, P. L., \& Province, J. M. (2012). Default Bayes factors for ANOVA designs. Journal of Mathemtaical Psychology, 56, 356e374. http://dx.doi.org/10.1016/j.jmp.2012.08.001.

Rouder, J. N., Speckman, P. L., Sun, D., Morey, R. D., \& Iverson, G. (2009). Bayesian t tests for accepting and rejecting the null hypothesis. Psychonomic bulletin \& review, 16(2), 225-237.

Salmelin, R., Hari, R. (1994). Spatiotemporal characteristics of sensorimotor neuromagnetic rhythms related to thumb movement. Neuroscience, 60, 537- 550 .

Schieber, M. H. (2001). Constraints on somatotopic organization in the primary motor cortex. Journal of Neurophysiology, 86, 2125-2143.

Schütz-Bosbach, S., Prinz, W. (2007). Perceptual resonance: action-induced modulation of perception. Trends Cogn Sci, 11, 349-355.

Shimazu, H., Maier, M.A., Cerri, G., Kirkwood, P.A., Lemon, R.N. (2004). Macaque ventral premotor cortex exerts powerful facilitation of motor cortex outputs to upper limb motoneurons. J Neurosci, 24, 1200 - 1211. Tettamanti, M., Buccino, G., Saccuman, M.C., Gallese, V., Danna, M. et al (2005). Listening to action-related sentences activates fronto- parietal motor circuits. J Cogn Neurosci, 17, 273-281.

Ticini, L. F., Schütz-Bosbach, S., Weiss, C., Casile, A., \& Waszak, F. (2012). When sounds become actions: Higher-order representation of newly learned action sounds in the human motor system. Journal of cognitive neuroscience, 24(2), 464-474.

Ticini, L.F., Schuetz-Bosbach, S., Waszak, F. (2017). Mirror and (absence of) counter-mirror responses to action sounds measured with transcranial magnetic stimulation. Soc Cogn Affect Neurosci, doi: $10.1093 / \mathrm{scan} / \mathrm{nsx} 106$ 
Umilta `MA, Escola L, Intskirveli I, Grammont F, Rochat M, Caruana F, Jezzini A, Gallese V, Rizzolatti G (2008) When pliers become fingers in the monkey motor system. Proc Natl Acad Sci U S A 105:2209 -2213. Umiltà, M.A., Kohler, E., Gallese, V., Fogassi, L., Fadiga, L., Keysers, C., Rizzolatti, G.(2001). I know what you are doing. A neurophysiological study. Neuron, $31, \quad 155-165$. Walker, M. P., Brakefield, T., Hobson, J. A., and Stickgold, R. (2003). Dissociable stages of human memory consolidation and reconsolidation. Nature 425, 616-620.

Waszak, F., Wascher, E., Keller, P., Koch, I., Aschersleben, G., Rosenbaum, D. A., \& Prinz, W. (2005). Intention-based and stimulus-based mechanisms in action selection. Experimental brain research, 162(3), 346356.

Watkins, K.E., Strafella, A.P., Paus, T. (2003). Seeing and hearing speech excites the motor system involved in speech production. Neuropsychologia, 41, 989-994.Wetzels, R., \& Wagenmakers, E. J. (2012). A default Bayesian hypothesis test for correlations and partial correlations. Psychonomic Bulletin \& Review, 19, 1057e1064. http://dx.doi.org/10.3758/s13423-012-0295-x.

Wilson, S.M., Saygin, A.P., Sereno, M.I., Iacoboni, M., 2004. Listening to speech activates motor areas involved in speech production. Nat Neurosci, 7, 701-702.

Wolpert, D. M., Diedrichsen, J., \& Flanagan, J. R. (2011). Principles of sensorimotor learning. Nature reviews. Neuroscience, 12(12), 739. 


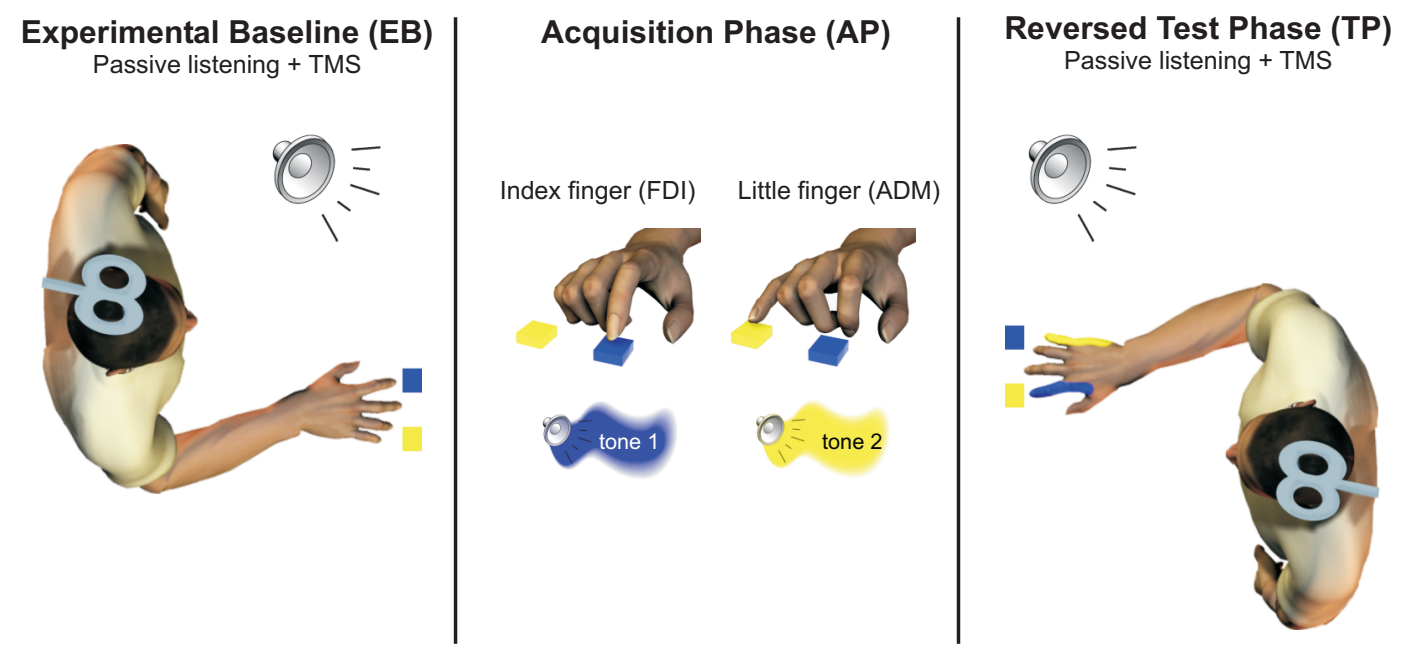

Figure 1
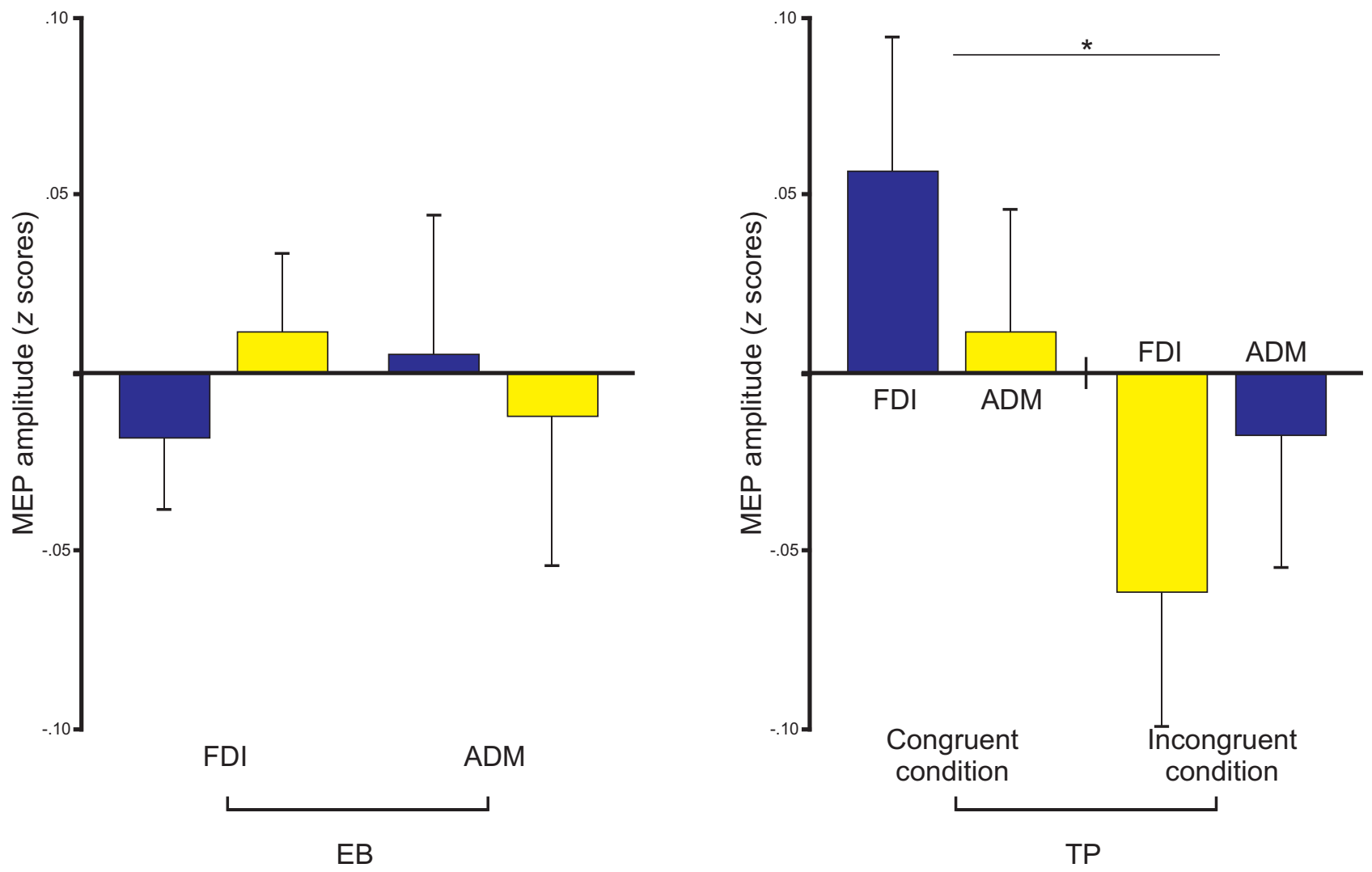

Figure 2 
Supplementary material for:

From goals to muscles: motor familiarity shapes the representation of action-related sounds in the human motor system.

Luca F. Ticini, Simone Schütz-Bosbach, Florian Waszak

\section{SUPPLEMENTARY METHODS}

\section{Participants and Experimental Protocol}

We determined the required size through the $\mathrm{G}^{*}$ power software (Faul, Erdfelder, Buchner, \& Lang, 2009) by setting the expected effect size at 0.66 (estimated from Ticini et al., 2012), the significance level at 0.05 , and the desired power at 0.96 .

The two MIDI tones (either 400 or $800 \mathrm{~Hz}$, lasting $200 \mathrm{msec}$; SOA of $0 \mathrm{msec}$; instrument marimba) were randomly presented to the participants binaurally, through headphones.

To assess the attention of the participant, we introduced four catch trials (eight in EB) at a random time, in which the experimenter asked to the participant "Which tone have you just heard?" (answer: low/high).

Each TMS pulse (Magstim 200, Whitland, UK) was randomly delivered at three different time intervals (50, 150 and $300 \mathrm{~ms})$ from the onset of the tone, for a total of 36 MEPs per tone in both EB and TP.

The inter-stimulation interval was of 10 to 12 seconds. We used a $70 \mathrm{~mm}$ figure-of-eight stimulation coil positioned tangentially over the optimal scalp position (in the left hemisphere) from which MEPs with maximal amplitude were elicited (at constant intensity) in both resting ADM and FDI finger muscles. The handle was oriented backward and laterally $45^{\circ}$ away from the midline approximately perpendicular to the central sulcus. The TMS intensity was set at $120 \%$ of each subject's resting motor threshold (rMT), defined as the lowest stimulator output sufficient to elicit five out of ten successive MEPs of $\geq 50 \mu \mathrm{V}$ in the relaxed ADM. Electromyographic $(\mathrm{EMG})$ signal was recorded with $\mathrm{Ag}-\mathrm{AgCl}$ surface electrodes fixed on the skin with a belly-tendon montage, then amplified (gain: $\times 1000)$, filtered $(10-1000 \mathrm{~Hz}$ bandpass), digitised at $5 \mathrm{kHz}$ (with a main hum notch filter at $50 \mathrm{~Hz}$ ), displayed on the computer screen and finally stored for off-line analysis. No particular discomfort or negative side-effects were reported. 


\section{Data analysis}

In all participants, individual peak-to-peak MEP amplitudes were calculated as the absolute distance between the minimum and maximum values observed within a search window starting at $10 \mathrm{msec}$ and ending at $80 \mathrm{msec}$ after the TMS pulse. We discarded trials with extremes values (SPSS Inc.) in peak-to-peak amplitudes or in the background EMG activity preceding the TMS pulse, or with exceeding 2.5 SD the mean of each participant, muscle and session (EB or TP; total percentage omitted: 7.7\%). For each participant, mean values were obtained from $33.2 \pm 3.3($ mean $\pm \mathrm{SD})$ MEP per condition.

Table S1: raw mean MEPs amplitudes \pm standard errors in each experimental condition.

\begin{tabular}{lcclc} 
& \multicolumn{2}{c}{ Experimental Baseline (EB) } & \multicolumn{2}{c}{ Test Phase (TP) } \\
\cline { 2 - 4 } & Tone 1 & Tone 2 & Congruent & Incongruent \\
\hline FDI & $1.39 \pm 0.22$ & $1.41 \pm 0.21$ & $1.34 \pm 0.17$ & $1.29 \pm 0.19$ \\
\hline ADM & $1.09 \pm 0.16$ & $1.07 \pm 0.17$ & $0.82 \pm 0.09$ & $0.79 \pm 0.07$
\end{tabular}

\section{Supplementary references}

Faul, F., Erdfelder, E., Buchner, A. \& Lang, A. (2009): Statistical power analyses using G*Power 3.1: Tests for correlation and regression analyses. Behavior Research Methods, 41, 1149-1160.

Ticini, L. F., Schütz-Bosbach, S., Weiss, C., Casile, A., \& Waszak, F. (2012). When sounds become actions: Higher-order representation of newly learned action sounds in the human motor system. Journal of cognitive neuroscience, 24(2), 464-474. 